\title{
Synthesis of $\mathrm{Au}-\mathrm{Ag}-\mathrm{Cu}$ trimetallic alloy nanoparticles prepared by electrical exploding wire technique in distilled water
}

\author{
Thikra K. Al-Kafaji and Hammad R. Humud \\ Department of Physics, College of Science, University of Baghdad, Baghdad, Iraq
}

E-mail: dr.hammad6000@yahoo.com

\begin{abstract}
Formation of $\mathrm{Au}-\mathrm{Ag}-\mathrm{Cu}$ ternary alloy nanoparticles (NPs) is of particular interest because this trimetallic system have miscible ( $\mathrm{Au}-$ $\mathrm{Ag}$ and $\mathrm{Au}-\mathrm{Cu})$ and immiscible $(\mathrm{Ag}-\mathrm{Cu})$ system. So there is a possibility of phase segregation in this ternary system. At this challenge it was present attempts synthetic technique to generate such trimetallic alloy nanoparticles by exploding wire technique. The importance of preparing nanoparticles alloys in distilled water and in this technique makes the possibility of obtaining nanoparticles free of any additional chemical substance and makes it possible to be used in the treatment of cancer or diseases resulting from bacterial or virus with least toxic. In this work, three metals alloys $\mathrm{Au}-\mathrm{Ag}-\mathrm{Cu}$ nanoparticles (A, B, and C) were prepared by exploding wire with different ratio of each elements. A high purity wire with diameters $(0.3 \mathrm{~mm})$ against plate of these alloys were held at $20 \mathrm{~V}$ with respect to the wire achieving different currents of 75,100 and $160 \mathrm{~A}$ in distilled water and then the size and a shape of the synthesized alloy nanoparticles modify by pulse laser with different energies, where the colloids of nanoparticles were exposed to one thousand pulses of $532 \mathrm{~nm}$ wavelengths per pulse from second harmonic Nd-YAG laser, after it has been focused by a lens with $15 \mathrm{~cm}$ focal length. The structural properties were studied using $\mathrm{x}$-ray diffraction. It was found that alloy nanoparticles with crystalline structure identical with face center cubic (fcc) and there is a new phase was appear for the A alloy this phase have the name tetragonal $\mathrm{AuCu}$. It can be concludes that electrical explosion wire in liquid medium (EEW) is promising technique for preparation metal alloy $\mathrm{Au}-\mathrm{Ag}$-Cu nanoparticles.
\end{abstract}

Key words

Exploding wire, $A u-$

Ag-Cu alloy nanoparticles, laser modification.

Article info.

Received: Jul. 2018

Accepted: Sep. 2018

Published: Dec. 2018

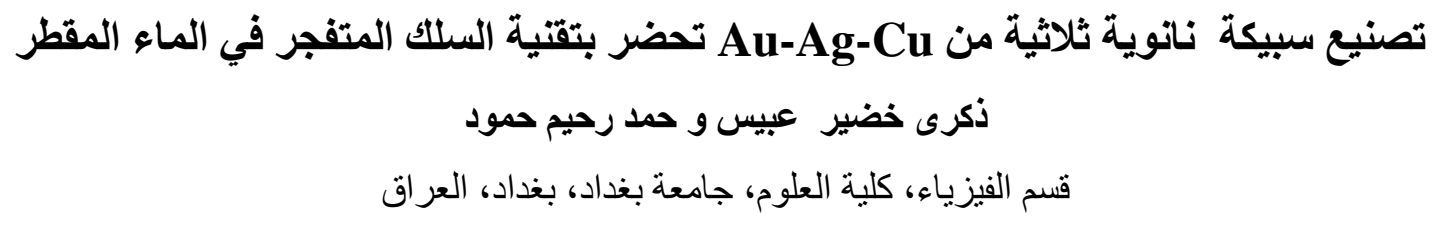

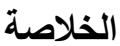

ان تشكيل سبيكة نانوية ثلاثية Au-Ag-Cu له أهمية خاصة لأن هذا النظام ثناثي الأطوار لديه نظام

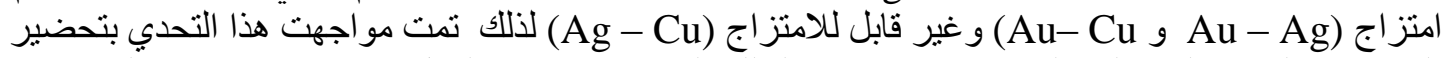

الجسيمات النانوية لهذه السبائك عن طريق تقنية السلك المتفجر. في هذا العمل، حضرت ثلانية ثلاثة سبائك معدنية

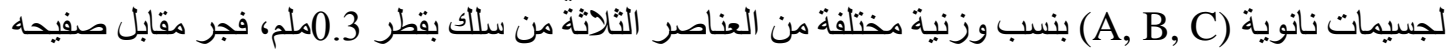

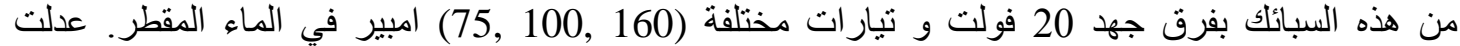

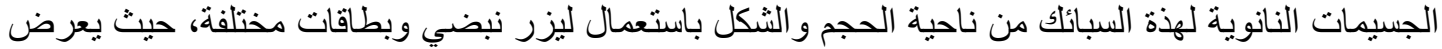

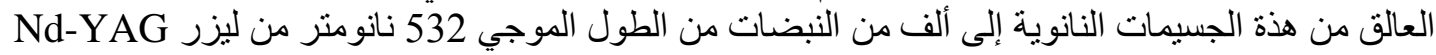




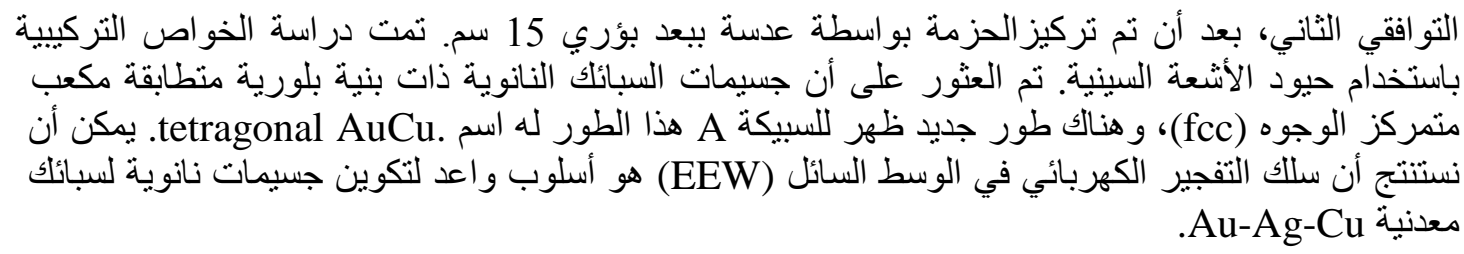

\section{Introduction}

Nanotechnology is one of the new technologies that deals with the progress in the systems, structures, and devices in nanometers scales [1]. Normally, decreasing the particle size of the material leads to gradually change the physical and chemical properties from the solid state to the molecular behavior [2]. It has remarkably revolutionized the technology sector in terms of the advancements in engineering, biomedical sciences, energy sector, health care and the major challenges in modern medicine (e.g. infectious diseases and cancers) [3]. The nanoparticles are produced by using various techniques like chemical methods, physical methods, and mechanical methods. One of the physical processes is the Electrical Explosion Wire (EEW) technique of producing nanoparticles, which has recently gained immense importance [4]. EEW method has become one of the promising ways for producing metal nanoparticles because it is ecologically safe, simple, effective, and cost-effective. This technique can be applied on gases and liquids for producing metal and multimetallic nanoparticles. In addition, it is capable of producing bulk amount of metal nanoparticles easily. Trimetallic nanoparticles have special magnetic, electronic, catalytic, optical properties and high chemical stability compared to their bimetallic or monometallic counterparts. The blending (as alloy) of two or more types of metals and their fine structures result in new surface characteristics [5]. The features of trimetallic alloy nanoparticles strongly depend on the composition, shape, and size. Thus, the structure of trimetallic alloy nanoparticles is defined by the distribution modes of the these elements. In addition, the structure of trimetallic nanoparticles can be oriented in random alloy, alloy with an intermetallic compound, cluster-incluster, and core-shell structures, leading to enhanced applications, compared to monometallic nanoparticles [6]. In fact, the most common alloy structures are intermetallic alloy and random alloy. The trimetallic alloy nanoparticles Ag$\mathrm{Au}-\mathrm{Cu}$ are mostly form intermetallic alloy structures due to the differences in the size and binding abilities of $\mathrm{Ag}$, $\mathrm{Au}$, and $\mathrm{Cu}$ [7]. The structure of trimetallic $\mathrm{Ag}-\mathrm{Au}-\mathrm{Cu}$ alloy nanoparticles has generated a lot of interest since it is known combination of which is likely to be useful catalytically [8].Solubility of trimetallic alloy constituents increases with decreasing particle size and this is one of the significant effects in formation of alloy nanoparticles, $\mathrm{Au}$ and $\mathrm{Ag}$ are both noble metals that full miscibility and high chemical stability so that possess excellent optical and electrical properties. Also, they display good corrosion resistant characteristic, this resulting synthesis of their nanoparticles can be easily achieved compare to other metals that tend to oxidize during synthesis. Copper $(\mathrm{Cu})$ is another metal that has comparable optical, thermal, and electrical properties with $\mathrm{Au}$ and $\mathrm{Ag}$. The only drawback is that $\mathrm{Cu}$ suffers for oxidation during nanoparticles synthesis process, and this becomes the 
major challenge [9]. $\mathrm{Cu}$ is the third metal having highest electrical conductivity. However, a slight decrease in its electrical properties occurs when it captures oxygen because copper oxide is relatively lower in conductance than pure copper. Hence, copper cannot be found in metallic form due its higher tendency towards oxidation. During oxidation of copper, oxygen forms a coat around it, causing a decrease in its electrical conductivity. Therefore, copper of trimetallic $\mathrm{Au}-\mathrm{Ag}-\mathrm{Cu}$ alloy nanoparticles can be prepared with $\mathrm{Au}$ and $\mathrm{Ag}$ which overcomes this problem [8]. The structure of $\mathrm{Ag}-\mathrm{Au}-\mathrm{Cu}$ alloy nanoparticles has generated a lot of interest since it is known that both $\mathrm{Au}$, $\mathrm{Ag}$ and $\mathrm{Cu}$ system have face centered cubic (fcc) structure and form a eutectic phase diagram. A strong (111) signature indicates that the alloy has a fcc lattice [10]. Furthermore that may be present the phase diagram at the nanoscale for the relevant distinct polyhedral morphologies of nanoparticles namely the tetrahedron (i.e $\mathrm{Au}-\mathrm{Cu}$ tetragonal) [11]. In this work, $\mathrm{Ag}-\mathrm{Au}-\mathrm{Cu}$ trimetallic alloy nanoparticles produced by the electroexploding wire (EEW) technique, a high magnitude of current $10^{10} \mathrm{~A} / \mathrm{m}^{2}$ passes through a metal wire in a short time of $10^{-6} \mathrm{~s}$ and converts the wire to a vapor state, The vaporized metal is then cooled down instantaneously to form nanoparticles [12]. Also, size and a shape of the synthesized alloy nanoparticles modify by shooting the colloidal with $532 \mathrm{~nm}$ second harmonic Nd-YAG laser pulses. The particle size reduction for alloy nanoparticle produced by thermal ablation. The laser causes melting and welding, giving rise to a large spherical shape particles. This occurs when the energy density of the laser pulses is insufficient to evaporate the particles the observed changes in the absorption spectra caused by laser irradiation appear to correspond to the changes in the size and shape of the particles [13].

\section{Experimental work \\ 1- Materials}

The metals which used in this work are silver, copper, and gold with prepare as alloys. The gold plate from Al-Sarmad Company in Al-Naher Street / Baghdad were used, 24 Karats (Karats measure the parts per 24), silver and copper are (Purity: 99.998\%; Alfa Asser) and we suggested alloys ratios as shown in Table 1.

Table 1: Alloys metal percentage.

\begin{tabular}{|c|c|}
\hline Alloy & Metals alloy ratios (Wt) \\
\hline & $50 \% \mathrm{Au}$ \\
$\mathbf{A}$ & $25 \% \mathrm{Ag}$ \\
& $25 \% \mathrm{Cu}$ \\
\hline & $25 \% \mathrm{Au}$ \\
B & $50 \% \mathrm{Ag}$ \\
& $25 \% \mathrm{Cu}$ \\
\hline & $15 \% \mathrm{Au}$ \\
$\mathbf{C}$ & $60 \% \mathrm{Ag}$ \\
& $25 \% \mathrm{Cu}$ \\
\hline
\end{tabular}

\section{2-Experimental setup}

In this work two electrodes, one in the form of wire and the other in the form of plate to produce the nanoparticles. This process was achieved by exploding a high purity Alloys wire $0.3 \mathrm{~mm}$ in diameter, against Alloy plate $(2 \times 1) \mathrm{cm}^{2}$ and (0.5) $\mathrm{mm}$ thickness held at $20 \mathrm{~V}$ with respect to the wire trying different current pulses of 75, 100 and $160 \mathrm{~A}$. The both plate and wire are cleaned with acetone after washed of distilled water before used. These explosions are carried out in a dispersed in $\left(60 \mathrm{~cm}^{3}\right)$ distilled water. To have a more modification nanoparticles the colloids exhibited to one thousand pulses of $532 \mathrm{~nm}$ wavelengths from the second harmonic Q-switched Nd/YAG laser system with maximum energy of $800 \mathrm{~mJ}$ per pulse, pulse width of $10 \mathrm{~ns}$, repetition rate $6 \mathrm{~Hz}$ and effective beam 
diameter of $5 \mathrm{~mm}$, trying different energies of 400, 600 and $800 \mathrm{~mJ}$ per pulse, after it has been focus by a lens with $15 \mathrm{~cm}$ focal length. Using $\mathrm{Nd}$ YAG laser with three different energies (400, 600 and $800 \mathrm{~mJ})$. Fig. 1 shows the system used to synthesize the Alloys nanoparticles by modified explosive wire in the form of pin plate.

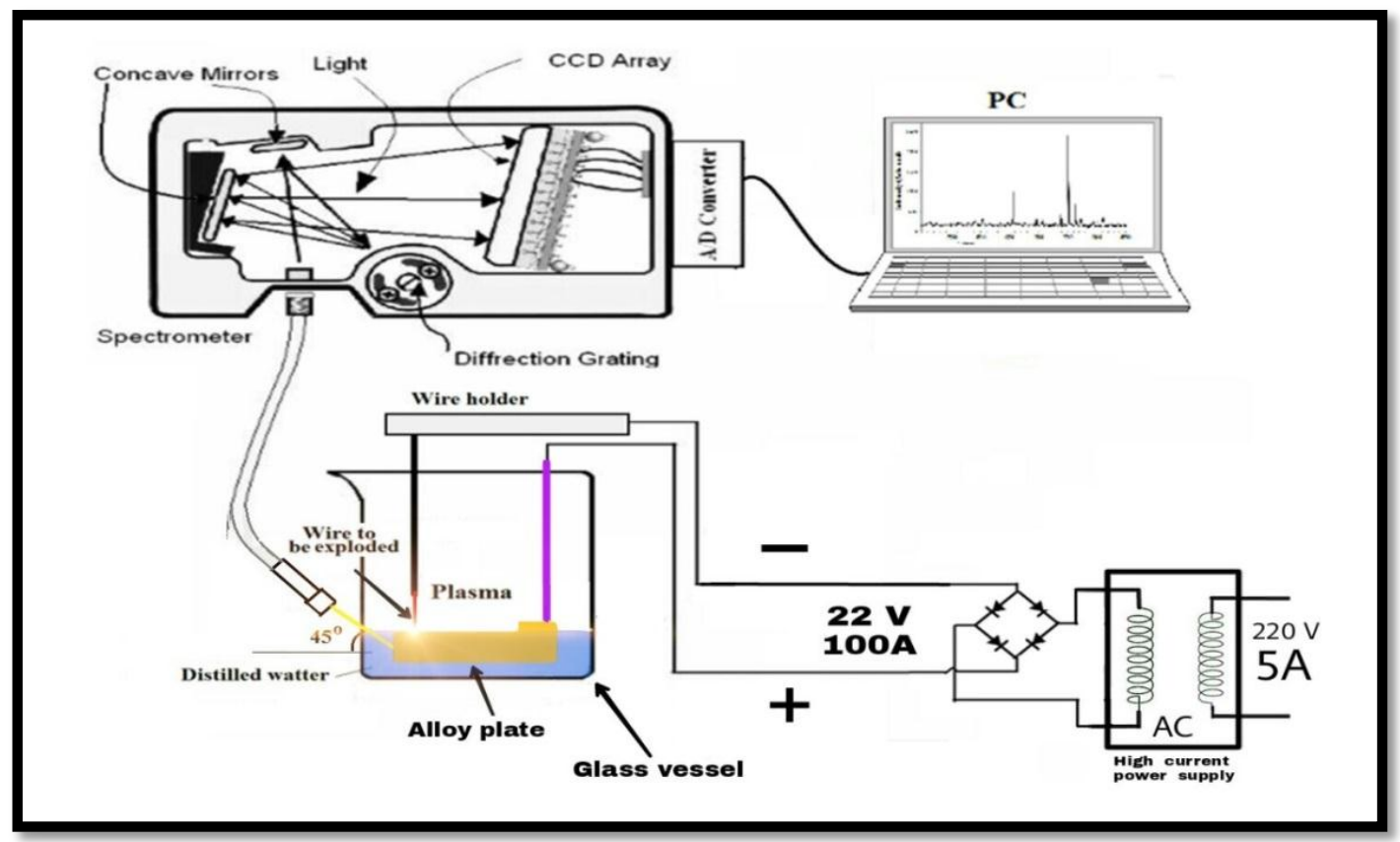

Fig. 1: Schematic diagram for alloys nanoparticles preparations and optical emission spectroscopy.

\section{Results and discussion}

$\mathrm{X}$-ray diffraction pattern is shown in Fig. 2, the diffraction peaks of the A-alloy were observed around $37.99^{\circ}$, $39.976^{\circ}, 43.4375^{\circ}, 46.538^{\circ}, 64.567^{\circ}$, $68.0769^{\circ}$ and $77.37^{\circ}$ which can be assigned to diffraction from (111), (101), (200), (110), (220), (200) and (311) planes respectively. The crystallite size was calculated by using the Scherer formula.

$D=k \lambda /(\beta \cos \theta)$ where $\lambda=$ wavelength of the radiation, $\beta=$ full width at half maximum, $\theta=$ Bragg's diffraction angle of the peak and $K=0.89$ (Scherer's constant).

It is obvious that the crystal structure of A-alloy was face center cubic (fcc). All peaks appear abroad, indicating the creation of NPs, the major peak with the highest of crystallinity. In this work, we have exclusively focused on diffraction from the (111) face. A strong (111) signature indicates that the alloy has a fcc lattice. Based on XRD patterns, it was concluded that the crystal structures are similar to those of facecentered cubic (fcc) crystals of Au, Ag, and $\mathrm{Cu}$. The formation of amorphous crystals was not observed neither peaks of $\mathrm{Cu}_{2} \mathrm{O}$ and $\mathrm{CuO}$, indicating that oxidation of the $\mathrm{Cu}$ component is negligible. The lattice parameter of pure $\mathrm{Au} / \mathrm{Ag}(0.408 \mathrm{~nm}$ for $\mathrm{Au}$ and $0.409 \mathrm{~nm}$ for $\mathrm{Ag}$ ) and larger than $\mathrm{Cu}$ $(0.361 \mathrm{~nm})$. Because the lattice parameter (fcc) of $\mathrm{Au}$ and $\mathrm{Ag}$ are similar, their peaks heavily overlap one another. Therefore, it was difficult to separate $\mathrm{Au}$ and $\mathrm{Ag}$ peaks that would not cause any modification after alloying. The shifting of the lattice parameter ' $a$ ' value indicates inclusion of $\mathrm{Cu}$ in the fcc structure to form 
$\mathrm{Cu}-\mathrm{Au}-\mathrm{Ag}$ nanoalloy, these is agreement with reported by previous studies $[11,14]$. Farther more in this alloy, a phase (tetragonal $\mathrm{AuCu}$ ) was observed, and the card No. was (01071-9135) [15].

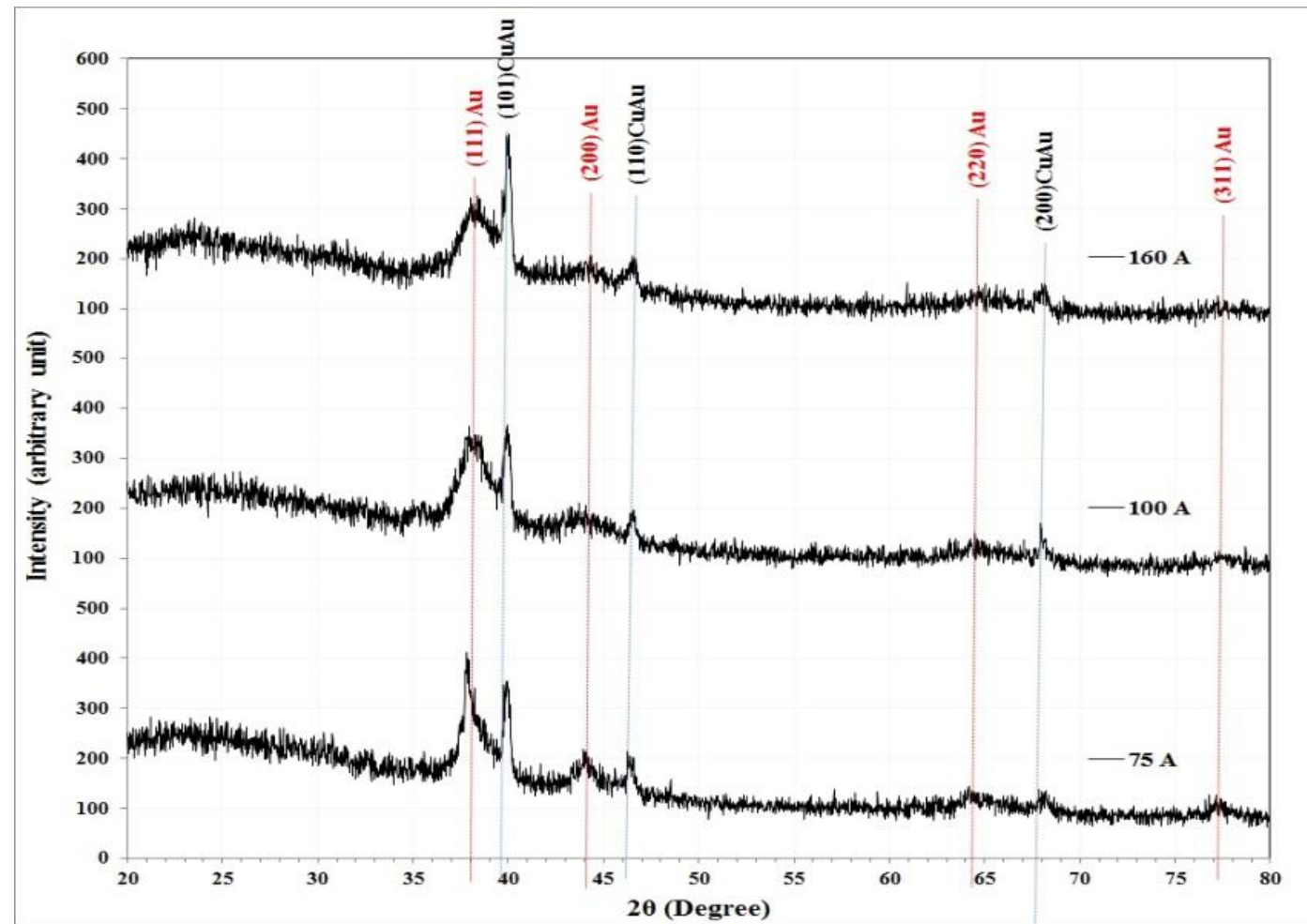

Fig. 2: X-ray diffraction pattern of A-alloy nanoparticles prepared by exploding of wire for a different current $(75 \mathrm{~A}, 100 \mathrm{~A}, 160 \mathrm{~A})$.

Fig. 3 shows the diffraction peaks of the B-alloy were seen at $37.95^{\circ}$, $44.2067^{\circ}, 64.4231^{\circ}$, and $77.4038^{\circ}$ which can be assigned to diffraction from (111), (200), (220), and (311) planes respectively. It is obvious that the crystal structure of B-alloy was face center cubic (fcc) nanoparticles. The Scherer formula calculated the crystallite size.

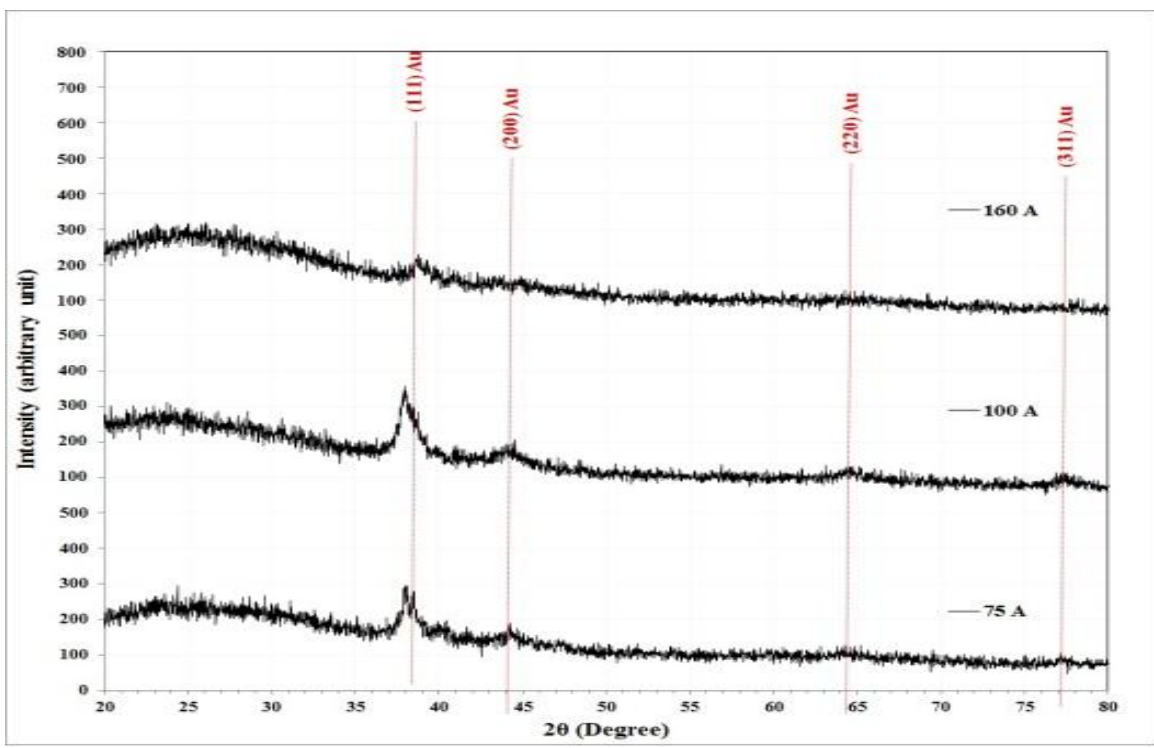

Fig. 3: X-ray diffraction pattern of B-alloy nanoparticles prepared by exploding of wire for a different current $(75 \mathrm{~A}, 100 \mathrm{~A}, 160 \mathrm{~A})$. 
Fig.4 represents the diffraction peaks of the C-alloy that were observed at $37.9178^{\circ}, 44.3029^{\circ}$, which can be assigned to diffraction from (111) and (200), planes respectively. It is obvious that the crystal structure of B-alloy was face center cubic (fcc) nanoparticles and the crystallite size was calculated by the Scherer formula.

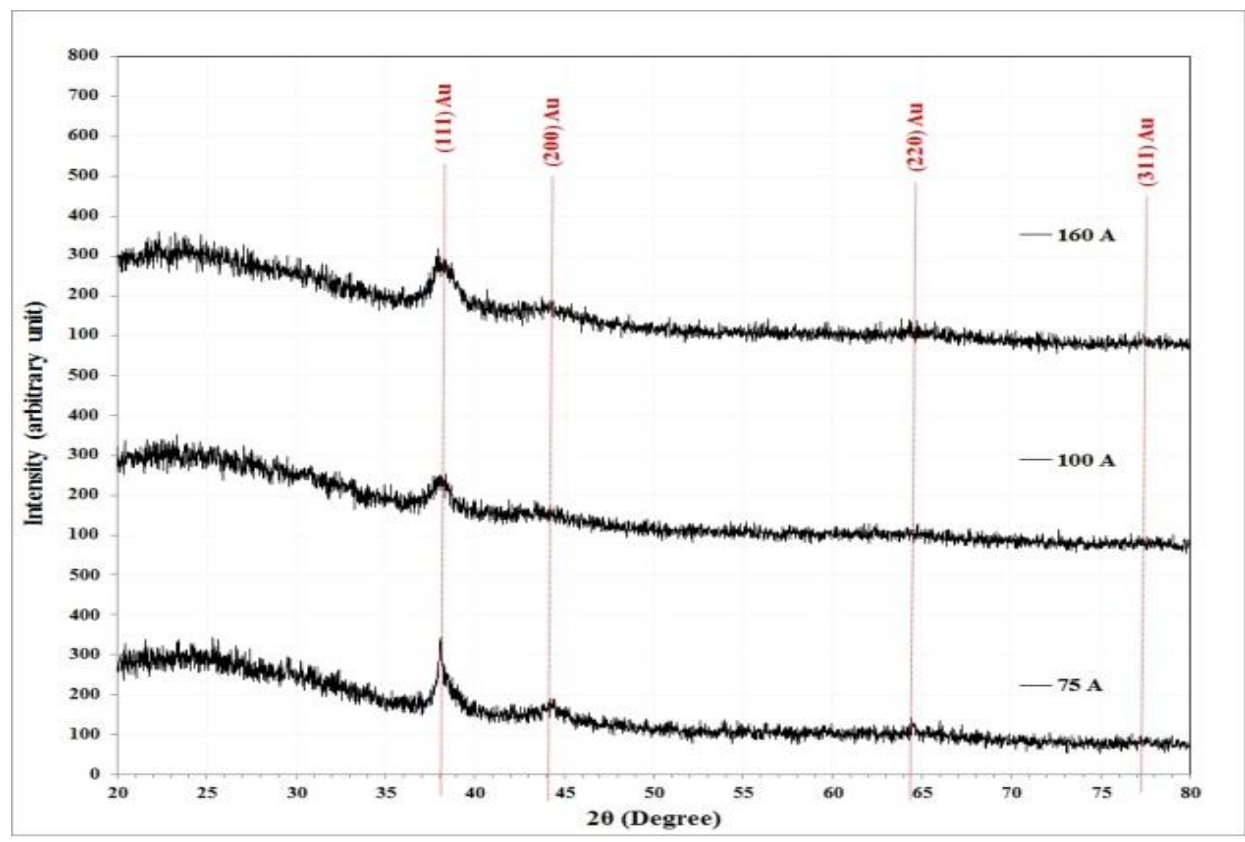

Fig. 4: $X$-ray diffraction pattern of $C$-alloy nanoparticles prepared by exploding of wire for a different current $(75 \mathrm{~A}, 100 \mathrm{~A}, 160 \mathrm{~A})$.

Figs. 5-7 show the X-ray diffraction pattern of the A-alloy NPs, synthesized by the laser irradiation. Different laser energies were used when the alloy NPs was done previously by 75A, 100A, 160A explosion current respectively. In Fig.5 diffraction peaks were recorded at $38.028^{\circ}, 40.120^{\circ}, 44.1542^{\circ}$ and $46.715^{\circ}$ which can be assigned to diffraction from (111), (101), (200) and (110) planes respectively. It is obvious that the crystal structure was face center cubic (fcc) noticed that when the laser pulse energy was increased the peaks intensities $\left(38.028^{\circ}\right)$ and less than the peaks intensities before exhibit laser energies Irradiation. While, the peaks intensities $\left(40.192^{\circ}\right)$ which represent the phase (tetragonal) noticed that in the case laser pulse energy $(400 \mathrm{~mJ})$ the peak disappear however in laser pulse energy $(800 \mathrm{~mJ})$ the peak is appear but faintly. 


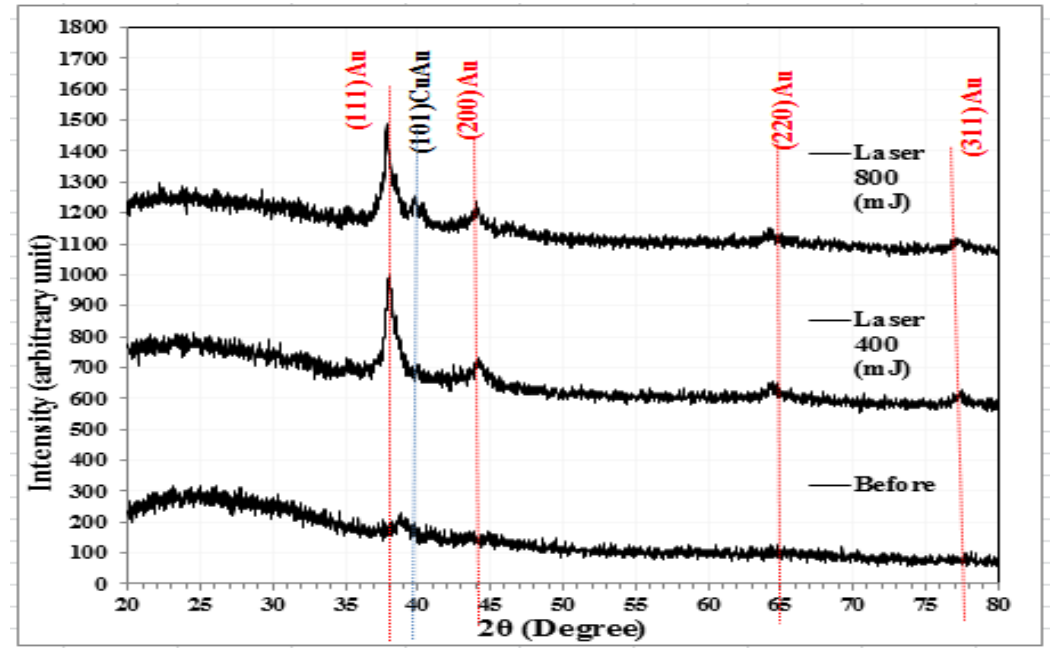

Fig. 5: X-ray diffraction pattern of A-alloy colloid NPs for exploding currents $75 A$ and synthesized by (400 m J, $800 \mathrm{~m} \mathrm{~J})$ laser energies Irradiation.

Fig.6 diffraction peaks were observed at $38.101^{\circ}, 40.192^{\circ}, 44.302^{\circ}$, which can be assigned to diffraction from (111), (101), (200), planes respectively. It is clear that the crystal structure was face center cubic (fcc) noticed that when the laser pulse energy was increased the peaks intensities $\left(38.028^{\circ}\right)$ was less than the peaks intensities before exhibit laser energies Irradiation. While, the peaks intensities $\left(40.192^{\circ}\right)$ which represent the phase (tetragonal) no longer observed with increasing laser pulse energy.

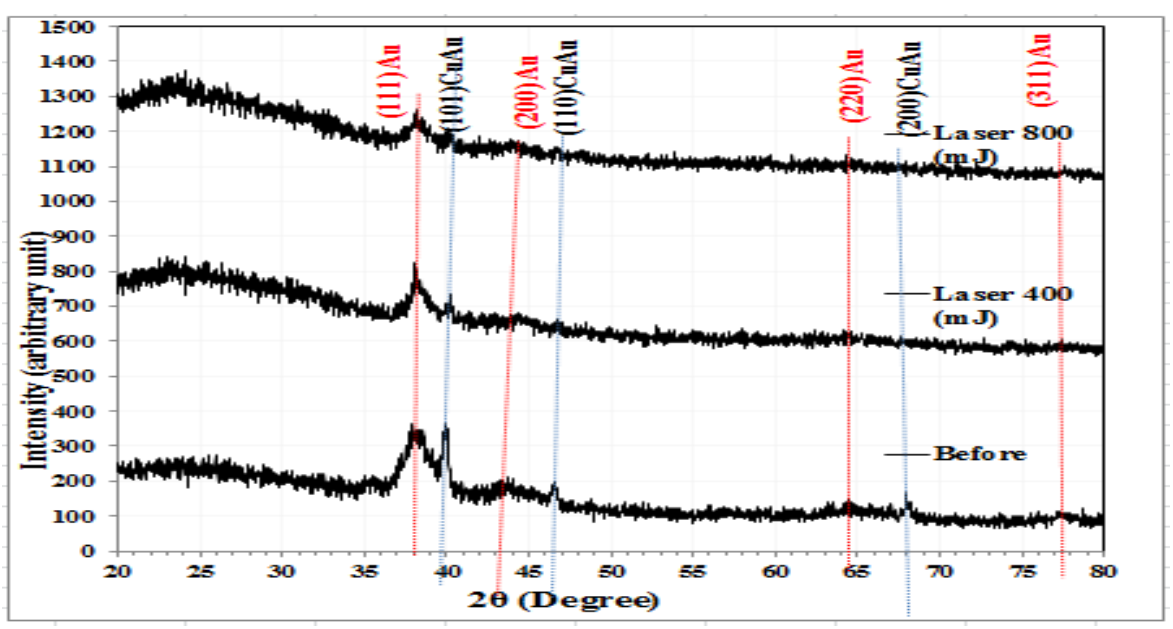

Fig. 6: X-ray diffraction pattern of A-alloy colloid NPs for exploding currents 100A and synthesized by (400 m J, $800 \mathrm{~m} \mathrm{~J}$ ) laser energies Irradiation.

In Fig.7, the diffraction peaks were recorded at $37.956^{\circ}, 40.120^{\circ}, 44.338^{\circ}$, $46.718^{\circ}, \quad 64.495^{\circ}, \quad 68.317^{\circ}, 77.541^{\circ}$ which can be assigned to diffraction from (111), (101), (200), (110), (220), (200) and (311) planes, respectively. It is clear that the crystal structure was face center cubic (fcc) noticed that when the laser pulse energy is increased the peaks intensities $\left(38.028^{\circ}\right)$ was increased compared to the peaks intensities before exhibited laser energies Irradiation while, the peaks intensities $\left(40.120^{\circ}\right)$ which is represent the phase (tetragonal) disbarred gradually with increasing laser pulse energy. 


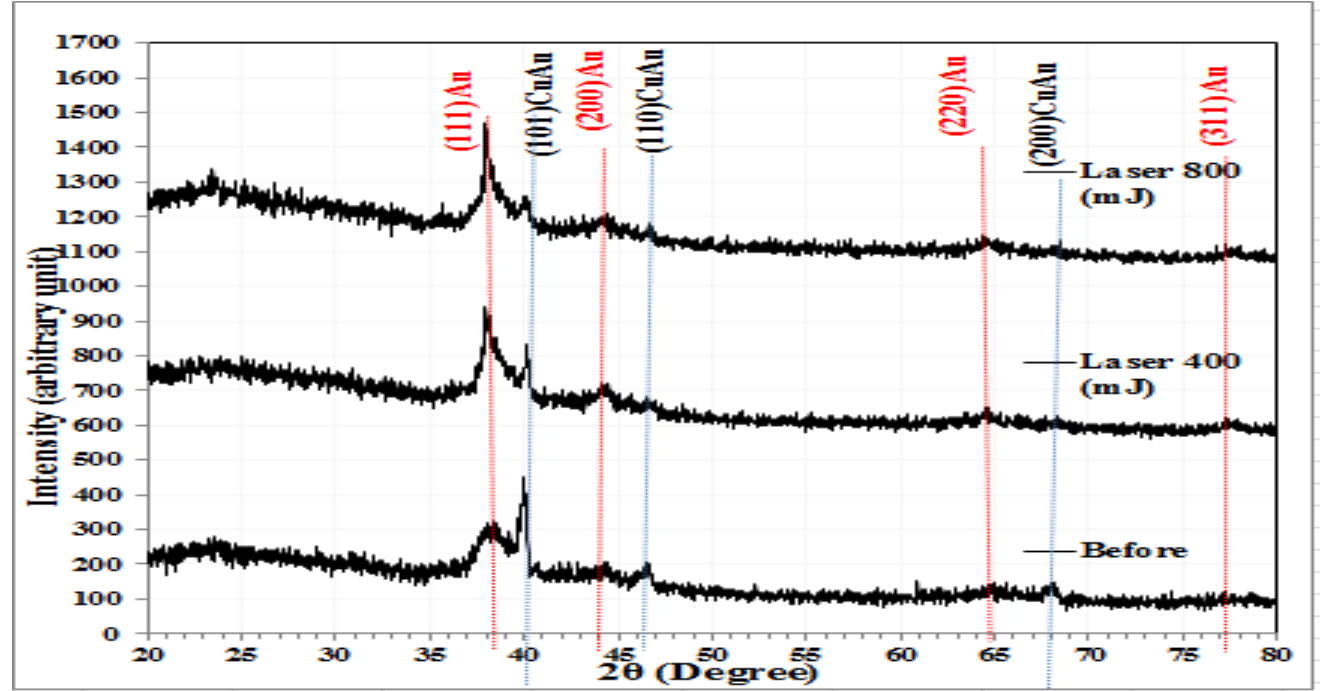

Fig. 7: X-ray diffraction pattern of A-alloy colloid NPs for exploding currents 160A and synthesized by (400 m J, $800 \mathrm{~m} \mathrm{~J}$ ) laser energies Irradiation.

Figs.8-10 show the X-ray diffraction pattern of the B-alloy NPs, synthesized by the laser Irradiation of the alloy with different laser energies. This was applied when the alloy NPs was synthesized previously by $75 \mathrm{~A}$, 100A, 160A explosion current respectively. In Fig. 8, diffraction peaks were recorded at $37.956^{\circ}$, $44.086^{\circ}, 64.495^{\circ}$ which can be assigned to diffraction from (111), (200), (220) planes respectively. It is clear that the crystal structure was face center cubic (fcc) noticed that when the laser pulse energy is increased $(400 \mathrm{~mJ})$ the peaks intensities $\left(37.956^{\circ}\right)$ was increased slightly compared to the peaks intensities before exhibited of laser energies Irradiation, while peak intensities is decreased when laser pulse energy is increased $(800 \mathrm{~mJ})$ which indicate to decreased the crystallite size (C.S nm).

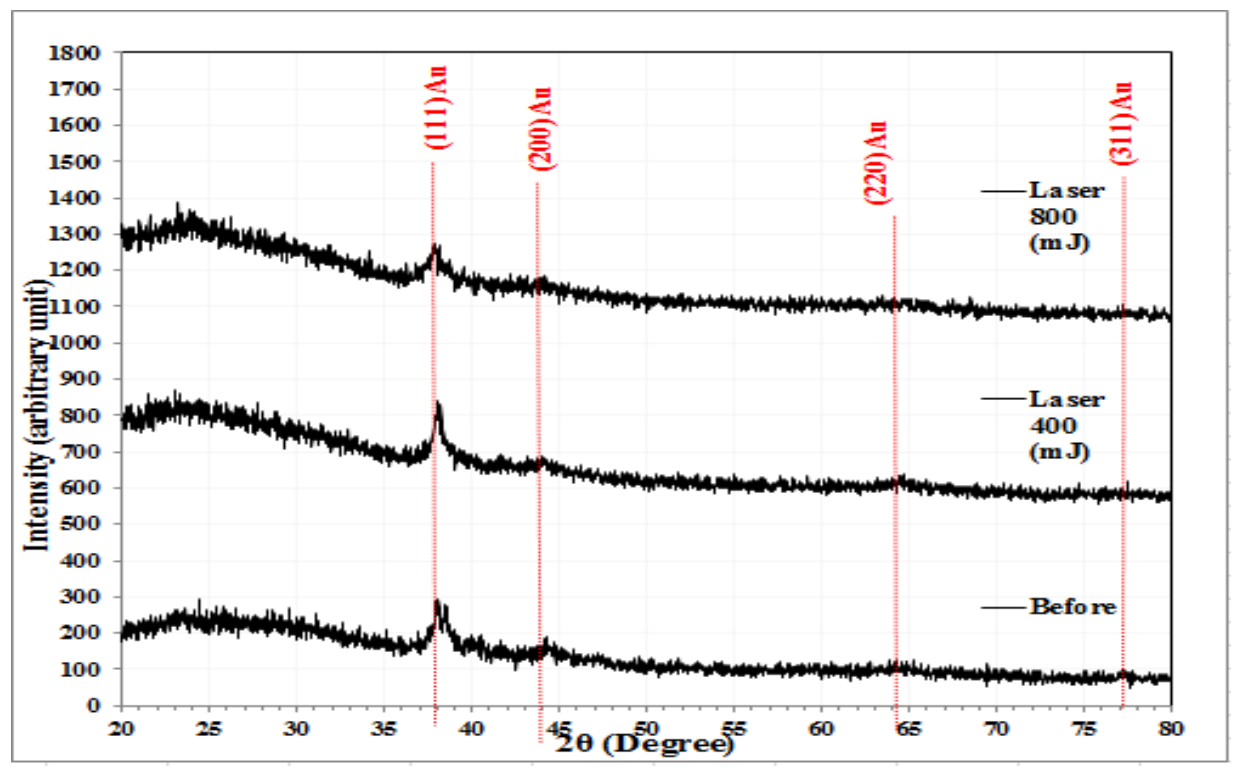

Fig. 8: X-ray diffraction pattern of B-alloy colloid NPs for exploding currents $75 A$ and synthesized by $(400 \mathrm{~m} \mathrm{~J}, 800 \mathrm{~m} \mathrm{~J})$ laser energies Irradiation. 
In Fig.9 diffraction peaks were seen around $38.06^{\circ}, 44.266^{\circ}, 64.63^{\circ}$ and $77.476^{\circ}$ which can be assigned to diffraction from (111), (200), (220) and (311) planes respectively. It is clear that the crystal structure was face center cubic (fcc) noticed that when the laser pulse energy is increased
$(400 \mathrm{~mJ})$ the peaks intensities $\left(38.06^{\circ}\right)$ was increased compared to the peaks intensities before exhibited of laser energies Irradiation, while peak intensities is decreased when laser pulse energy is increased $(800 \mathrm{~mJ})$ which indicate to decreased the crystallite size (C.S nm).

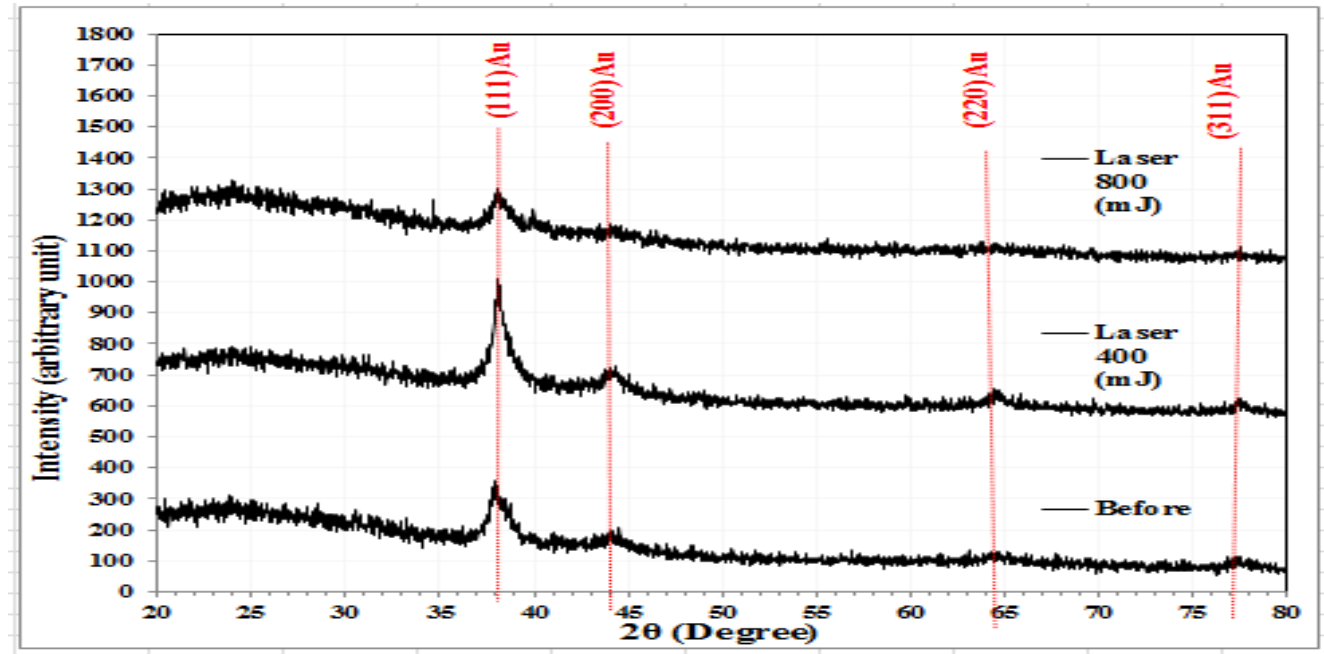

Fig. 9: X-ray diffraction pattern of B-alloy colloid NPs for exploding currents 100A and synthesized by (400 m J, $800 \mathrm{~m} \mathrm{~J})$ laser energies Irradiation.

In Fig.10 diffraction peaks were seen around $37.956^{\circ}, 39.903^{\circ} 44.122^{\circ}$, $64.385^{\circ}, \quad 77.4038^{\circ}$, and $77.2596^{\circ}$ which can be assigned to diffraction from (111), (101), (200), (220) (311) and (200) planes respectively. It is clear that the crystal structure was face center cubic (fcc) noticed when the laser pulse energy is increased
$(400 \mathrm{~mJ})$ the peaks intensities $\left(37.956^{\circ}\right)$ was increased compared of the peaks intensities before exhibited of laser energies Irradiation while peaks intensities $39.903^{\circ}$ and $77.2596^{\circ}$ is appear when laser pulse energy is increased $(800 \mathrm{~mJ})$ which may be is duo to of laser energies Irradiation.

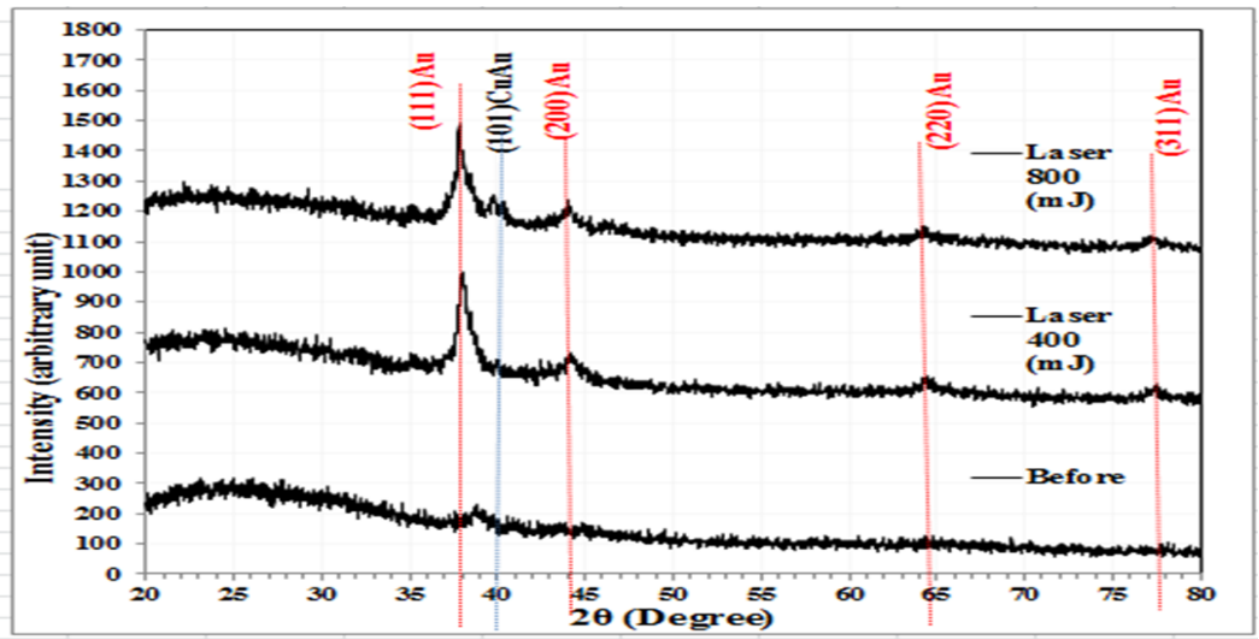

Fig. 10: X-ray diffraction pattern of B-alloy colloid NPs for exploding currents 160A and synthesized by (400 m J, $800 \mathrm{~m}$ J) laser energies Irradiation. 
Figs.11-13 show the X-ray diffraction pattern of the C-alloy NPs, synthesized by the laser Irradiation of the alloy with different laser energies. This was applied when the alloy NPs was synthesized previously by $75 \mathrm{~A}$, 100A, 160A explosion current respectively. In Fig. 11 diffraction peaks were seen around $38.016^{\circ}$, $44.266^{\circ}, 64.567^{\circ}$ and $77.62^{\circ}$ which can be assigned to diffraction from (111), (200), (220) and (200), planes respectively . It is clear that the crystal structure was face center cubic (fcc) noticed that when the laser pulse energy is increased $(400 \mathrm{~mJ})$ the peaks intensities $\left(38.016^{\circ}\right)$ was increased slightly compared of the peaks intensities before exhibited of laser energies Irradiation which abroad full width at half maximum which indicate to decreased the crystallite size (C.S nm) and peak intensities is increased when laser pulse energy is increased.

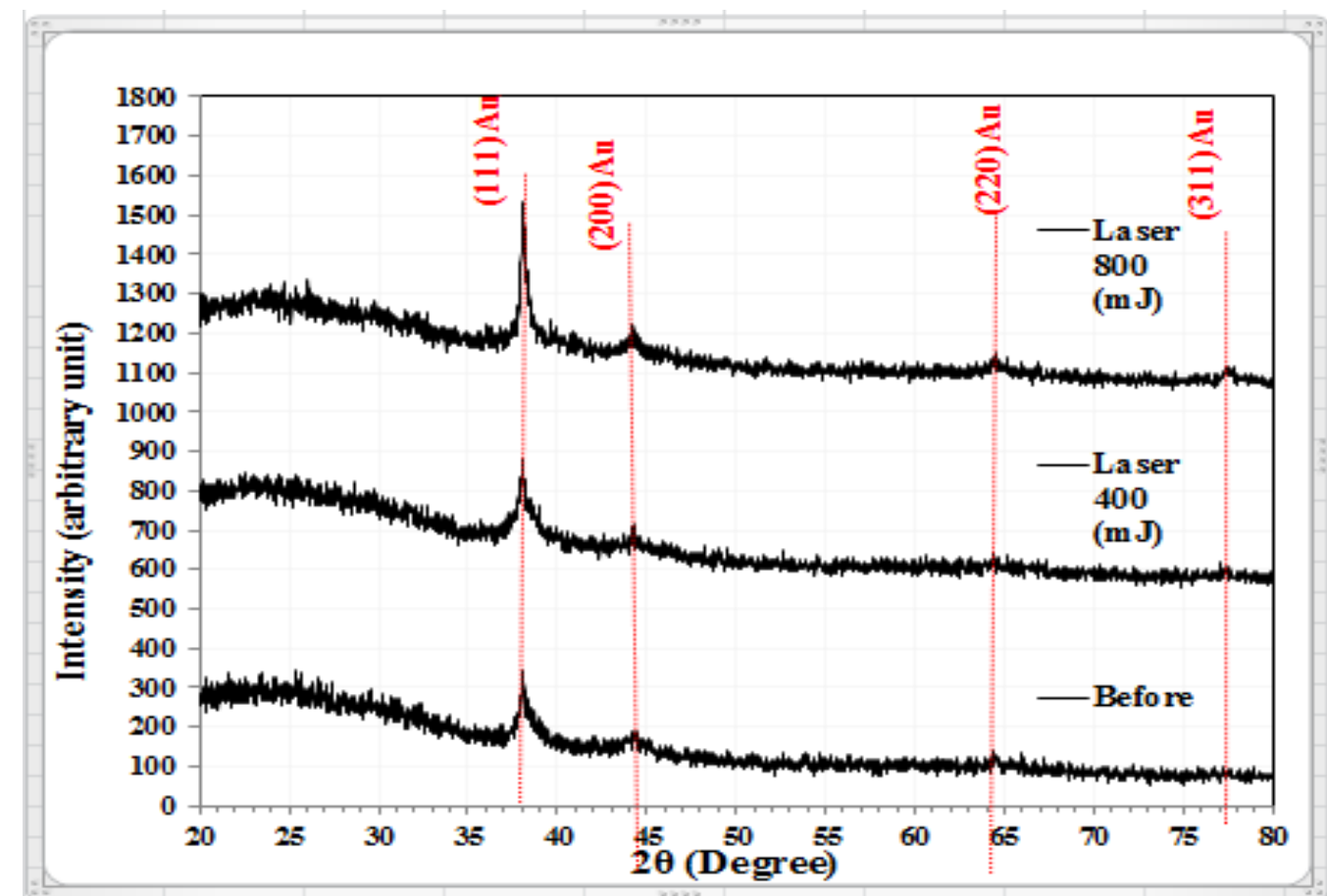

Fig. 11: $X$-ray diffraction pattern of C-alloy colloid NPs for exploding currents $75 A$ and synthesized by (400 m J, $800 \mathrm{~m} \mathrm{~J})$ laser energies Irradiation.

In Fig.12 diffraction peaks were seen around $38.045^{\circ}, 44.194^{\circ}, 64.387^{\circ}$ and $77.548^{\circ}$ which can be assigned to diffraction from (111), (200), (220) and (200), planes respectively. It is clear that the crystal structure was face center cubic (fcc) noticed when the laser pulse energy is increased (400 $\mathrm{mJ})$ the peaks intensities $\left(38.045^{\circ}\right)$ was increased longer with compared of the peaks intensities before exhibited of laser energies Irradiation which narrow full width at half maximum which indicate to increase the crystallite size (C.S nm) and peak intensities is decreased when laser pulse energy is increased $(800 \mathrm{~mJ})$ which indicate to decreased the crystallite size (C.S nm). 


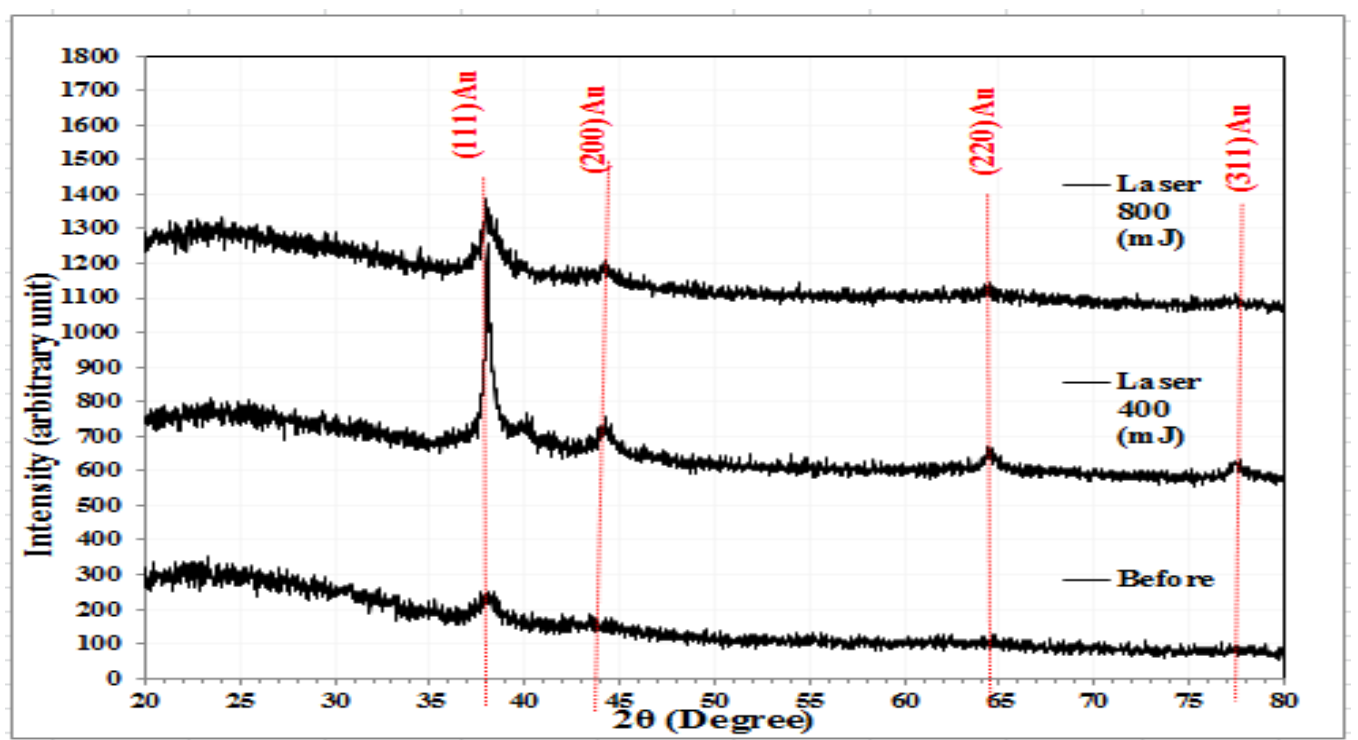

Fig. 12: X-ray diffraction pattern of C-alloy colloid NPs for exploding currents 100A and synthesized by (400 m J, $800 \mathrm{~m} \mathrm{~J}$ ) laser energies Irradiation.

In Fig.13 diffraction peaks were seen around $38.028^{\circ}, 44.265^{\circ}, 64.361^{\circ}$ and $77.476^{\circ}$ which can be assigned to diffraction from (111), (200), (220) and (311), planes respectively. It is clear that the crystal structure was face center cubic (fcc) noticed when the laser pulse energy is increased $(400 \mathrm{~mJ})$ the peaks intensities $\left(38.028^{\circ}\right)$ was increased longer compared of the peaks intensities before exhibited of laser energies Irradiation which abroad full width at half maximum which indicate to decreased the crystallite size (C.S nm) and peak intensities is decreased slightly when laser pulse energy is increased $(800 \mathrm{~mJ})$.

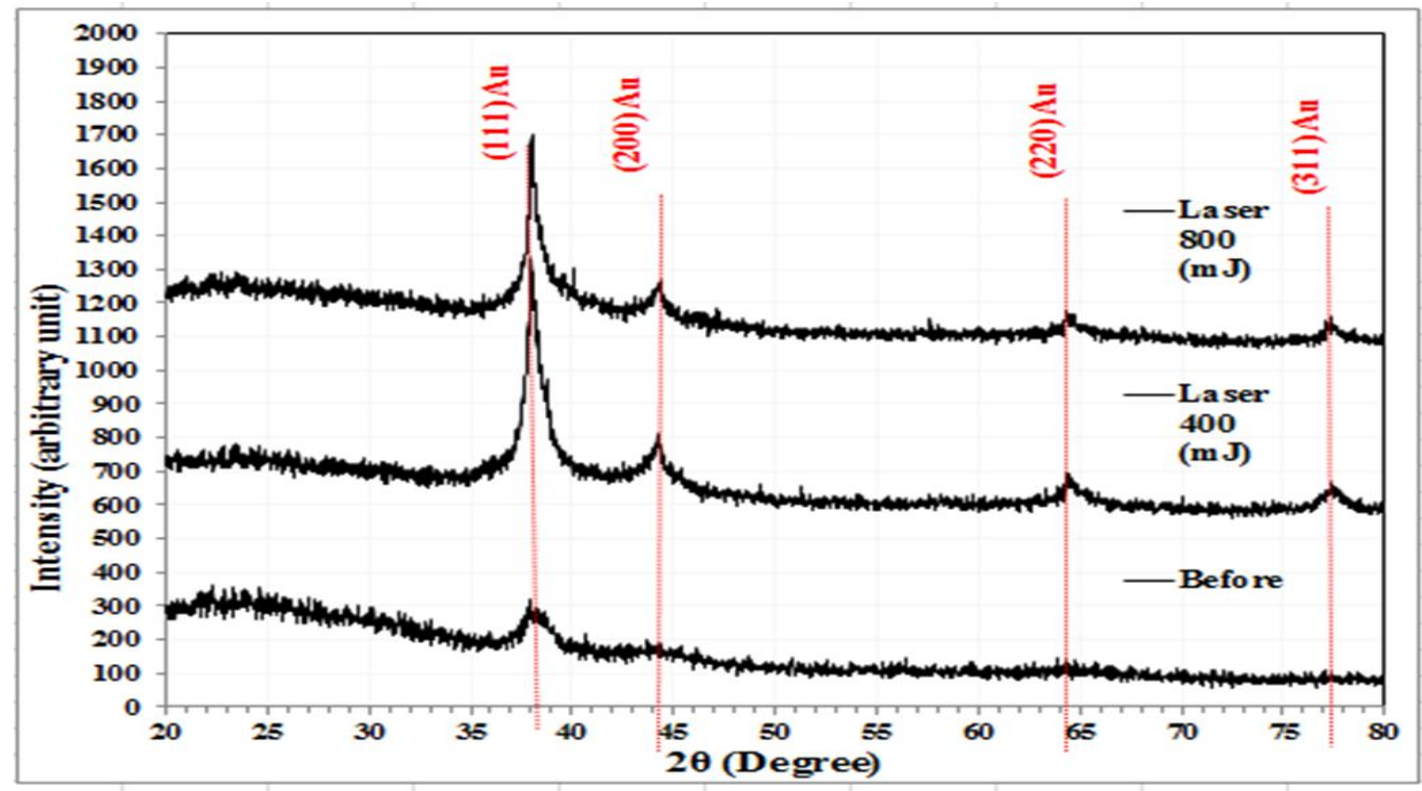

Fig. 13: X-ray diffraction pattern of C-alloy colloid NPs for exploding currents $160 \mathrm{~A}$ and synthesized by $(400 \mathrm{~m} \mathrm{~J}, 800 \mathrm{~m} \mathrm{~J})$ laserenergies Irradiation. 


\section{Conclusions}

Our results, in a study the electrical explosion wire (EEW) in liquid medium is promising technique for preparation metal alloy $\mathrm{Au}-\mathrm{Ag}-\mathrm{Cu}$ nanoparticles. Also there is a possibility to modify the nanoparticles size and a shape by change of pulse laser energy. The structural properties were studied using $x$-ray diffraction. It was found that alloy nanoparticles with crystalline structure identical with face center cubic (fcc), and the results shows there is a new phase was appear when examining the A- alloy by the $\mathrm{X}$ ray diffraction this phase have the name tetragonal $\mathrm{AuCu}$ (cared No.(01071-9135)).

\section{References}

[1] K. F. Schmidt "Nanofrontiers Visions for the Future of Nanotechnology", International center for scholars Project on Emerging Nanotechnologies PEN 6 March 2007.

[2] C. Minelli," Bottom-up Approaches for Organizing Nanoparticles with Polymers", Ph. D Thesis, Lausanne, Switzerland, PP. 7-9, 2004.

[3] A. O. Salama Amira A. El-Adly, H. M. Abdel-Aleam, Journal of Medical Microbiology, 64 (2015) 1151-1161.

[4] P. Wankhede, P. K. Sharma, A. K. Jha J. Eng. Res. Appl., 3, 6 (2013) 1664-1669.

[5] T. Masaharu, M. Mika, K.Hisayo, O. Masatoshi, H.Sachie, Y.Yuki, I.Toshitaka, Journal the Royal Society of Chemistry 15 (2013) 1345-1351.

[6] M. Paszkiewicz, G.Anna, Aukasz Rajski, K.Ewelina, S.Agnieszka, Z. Adriana, Journal of Nanomaterials, 2016 (2016) 1-13.
[7] Latif-ur-Rahman, Afzal Shah, Rumana Qureshi, Sher Bahadar Khan, Abdullah M. Asiri, Anwar-ul-Haq Ali Shah, Muhammad Ishaq, Mohammad Saleem Khan, Suzanne Kay Lunsford, andMuhammad Abid Zia, Advances in Materials Science and Engineering, 2015 (2015) 1-8.

[8] R. G.Haverkamp, A. T. Marshall, D. Van Agterveld, Journal of Nanoparticle Research, 9 (2007) 697700.

[9] Kim Seah Tan, Kuan Yew Cheong, J. Nanopart Res., 15, 1537 (2013) 129.

[10] Yoshikazu Hashimoto, Gediminas Seniutinas, Armandas Balčyti, Saulius Juodkazis, Yoshiaki Nishijima, Scientific Reports, 6 (2016) 1-9.

[11] G. Grégory, R.- Mejia Sergio, K.Subarna,R.Z. Francisco, L. W. Robert, J. Y. Miguel, NanoLetters 10 (2014) 6718-6726.

[12] R. H. Hammad, M.M.Aqeel, A. G.Mohammed, American Journal of Engineering Research (AJER), 6, 6 (2017) 117-122.

[13] X. Li, M. Cao, H. Zhang, L. Zou, S. Cheng, J. Yao, L. Fan, Journal of Colloid and Interface Science, 328 (1) (2012) 28-35.

[14] P. Sudipto, B. Sandip, D. Goutam, Journal of Nanoscience and Nanotechnology, 10 (2010) 775-783.

[15] S. Ishibata, Kogachi, M.Nippon, K. Gakkaishi, J. Jpn. Inst. Mrt., 47, 921, (1982). 